\title{
Determination of fungal activity in modified wood by means of micro-calorimetry and determination of total esterase activity
}

\author{
Pradeep Verma • Jens Dyckmans • Holger Militz • \\ Carsten Mai
}

Received: 30 January 2008 /Revised: 29 April 2008 / Accepted: 29 April 2008 / Published online: 10 June 2008

(C) The Author(s) 2008

\begin{abstract}
Beech and pine wood blocks were treated with 1,3-dimethylol-4,5-dihydroxyethylen urea (DMDHEU) to increasing weight percent gains (WPG). The resistance of the treated specimens against Trametes versicolor and Coniophora puteana, determined as mass loss, increased with increasing WPG of DMDHEU. Metabolic activity of the fungi in the wood blocks was assessed as total esterase activity (TEA) based on the hydrolysis of fluorescein diacetate and as heat or energy production determined by isothermal micro-calorimetry. Both methods revealed that the fungal activity was related with the WPG and the mass loss caused by the fungi. Still, fungal activity was detected even in wood blocks of the highest WPG and showed that the treatment was not toxic to the fungi. Energy production showed a higher consistency with the mass loss after decay than TEA; higher mass loss was more stringently reflected by higher heat production rate. Heat production did not proceed linearly, possibly due to the inhibition of fungal activity by an excess of carbon dioxide.
\end{abstract}

Keywords Brown rot · Fungal activity · Micro-calorimetry . Total esterase activity . White rot $\cdot$ Wood modification

P. Verma $\cdot$ H. Militz $\cdot$ C. Mai $(\bowtie)$

Wood Biology and Wood Products, Burckhardt Institute,

Georg-August-University Göttingen,

Büsgenweg 4,

37077 Göttingen, Germany

e-mail: cmai@gwdg.de

\section{J. Dyckmans}

Centre for Stable Isotope Research and Analysis, Büsgen Institute,

Georg-August-University Göttingen,

Büsgenweg 2,

37077 Göttingen, Germany

\section{Introduction}

Chemical modification of solid wood is a novel technology to achieve protection of wood exposed to outdoor weathering conditions. The technology aims at enhancing the durability of wood in terms of resistance against wood decay fungi and insects. Chemical modification can also improve various material properties of wood such as dimensional stability, compression strength, hardness, as well as weathering and UV stability (Hill 2006). The main processes which have been applied to chemically modify wood are acetylation (Goldstein et al. 1961; Militz 1991; Rowell 2006; Hill and Jones 1999), treatment with aldehydes or ketones (Akitsu et al. 1993; Yano and Minato 1993; Yasuda and Minato 1994) and furfurylation (Lande et al. 2004). Another very promising process is the treatment of wood with 1,3-dimethylol-4,5-dihydroxyethylene urea (DMDHEU). In the preceding studies, wood modification with DMDHEU was shown to increase resistance against decay fungi, to improve dimensional stability and to slightly reduce the moisture uptake of wood (Militz 1993; Yasuda and Minato 1994; Yusuf 1996; Kabir et al. 1992).

The general principle of chemical wood modification is the reaction of a chemical agent with functional groups (mostly hydroxyl groups) of the cell wall polymers (cellulose, hemicellulose, lignin) and the formation of covalent bonds. This causes a change in the chemical and physical characteristics of wood (Rowell 1983; Norimoto 2001; Hill 2006). Due to the introduction of bulkier groups within the cell wall, the dimensions of the cell wall increase and the pore size is reduced (Hill and Jones 1996; Kwon et al. 2007). As a result, the dimensional stability generally increases and the equilibrium moisture content decreases, since less space is available between the cell wall polymers to incorporate water molecules. The fibre saturation point 
of wood (approximately 25-35\%) is an important factor for fungal colonisation of wood. Fungi require wood moisture content above fibre saturation, because under these conditions free water is available in the lumens of the wood cells (Eaton and Hale 1993).

High resistance against fungal decay is assumed to be due to changes in the material properties of wood rather than a toxic effect on fungal physiology. This implies that modified wood can principally be colonised by decay fungi, since modified wood is not toxic to the fungi, but degradation of the modified cell wall is impeded (Hill 2006).

Studies on the resistance of modified wood to fungal degradation are almost exclusively based on standard test procedures which are limited to the determination of mass loss and/or loss of dynamic modulus of elasticity (MoE). Few studies have addressed the protection mechanisms of wood modification against decay fungi (Ohkoshi et al. 1999; Ritschkoff et al. 1999; Papadopoulos and Hill 2002; Mohebby and Militz 2002). Activity of decay fungi in wood is usually assessed by measuring the linear growth of the fungal hyphae or the mass loss of the infected wood. In addition, respiration, i.e. production of carbon dioxide (Weigenand et al. 2008), ATP or ergosterol (Bjurman $1992,1994)$ has been used to evaluate microbial activity. In this study, determination of total esterase activity and micro-calorimetry were used to estimate the colonisation and biomass production on untreated and DMDHEUmodified wood. The determination of the total esterase activity of the fungi is based on hydrolysis of fluorescein diacetate (FDA, 3,6-diacetoxyfluoran). FDA is cleaved to fluorescein and acetic acid by different enzymes, such as proteases, lipases and esterases (Guilbault and Kramer 1964). These enzymes are constituents of the primary metabolism of micro-organisms (Swisher and Carroll 1980). Released fluorescein can be quantified by fluorometry or spectrophotometry (Schnürer and Rosswall 1982; Kerem et al. 1992; Bjurman 1993) or localised by fluorescence microscopy (Saxena and Lysek 1993).

Isothermal micro-calorimetry has been used as a nondestructive technique that requires only small sample volumes, is easy to handle and displays high reproducibility and sensitivity (Criddle et al. 1991). A micro-calorimeter determines the heat production rate (microwatt) in an adiabatic system, where heat is created by chemical reactions or the metabolic activity of living organisms. The total (net) heat output is equal to the metabolic enthalpy change and can be divided into a catabolic and an anabolic change (Dermoun and Belaich 1980). Catabolic metabolism, however, constitutes the main part of metabolism in terms of energy release. It was estimated that anabolic metabolism contributed $1.5 \%$ to the total heat production for oxic growth of yeast and bacteria and $8 \%$ for anoxic growth (Belaich 1980; Larsson et al. 1991). The released heat is proportional to the consumption of nutrients as long as the mode of metabolism does not change (Xie et al. 1997). This technique has been used previously to determine the microbial activity in soils (Vor et al. 2002; Dyckmans et al. 2006) and of yeasts (Ölz et al. 1993). Only a few studies describe the use of micro-calorimetry to determine the physiological activity of rotting fungi (Ginterova and Lazariva 1989; Xie et al 1997; Bjurman and Wadso 2000). Heat production caused by fungi in an infected wood block can be directly related to the mass loss of the same block; for total esterase activity (TEA) determination, however, the wood samples need to be crushed and degradation products leach out during the test in aqueous solution. Therefore the mass loss after testing is difficult to determine.

\section{Materials and methods}

\section{Micro-organisms}

The brown rot fungus Coniophora puteana (Schum.: Fr.) Karst. strain BAM Ebw. 15 (DSM 3085) and the white rot fungus Trametes versicolor (Linneus) L. Quélet strain CTB 863 A (DSM 3086) were obtained from the Federal Agency of Material Research (BAM). The cultures were maintained on $4 \%$ malt extract agar medium at $22^{\circ} \mathrm{C}$; sub-culturing was done twice a month to check virulence of test organisms on wood.

\section{Wood samples and impregnation with DMDHEU}

Mini-blocks (30 [longitudinal] $\times 10 \times 5 \mathrm{~mm}^{3}$ ) of beech (Fagus sylvatica L.) and pine sapwood (Pinus sylvestris L.) were vacuum pressure impregnated at $100 \mathrm{mbar}(1 \mathrm{~h})$ and 12 bar $(1 \mathrm{~h})$ with aqueous solutions which contained $0.12 \mathrm{~mol} \mathrm{l}^{-1}\left(7.3 \mathrm{mmol} \mathrm{l}^{-1}\right), 0.24 \mathrm{~mol} \mathrm{l}^{-1}\left(14.7 \mathrm{mmol} \mathrm{l}^{-1}\right)$, $0.40 \mathrm{~mol} \mathrm{l}^{-1}\left(24.9 \mathrm{mmol} \mathrm{l}^{-1}\right), 0.83 \mathrm{~mol} \mathrm{l}^{-1}\left(51.7 \mathrm{mmol} \mathrm{l}^{-1}\right)$ and $1.77 \mathrm{~mol} \mathrm{l}^{-1}\left(110.9 \mathrm{mmol} \mathrm{l}^{-1}\right)$ of DMDHEU (BASF, Ludwigshafen, Germany) and of $\mathrm{MgCl}_{2} \cdot 6 \mathrm{H}_{2} \mathrm{O}$ (in brackets).

After impregnation, the specimens were removed from the treatment solution, pre-dried at room temperature for $24 \mathrm{~h}$ and subsequently dried at $120^{\circ} \mathrm{C}$ for $24 \mathrm{~h}$. The weight percent gain (WPG) was calculated from the dry masses before and after treatment as previously described (Donath et al. 2004). Twelve replicates were used per treatment $(n=12)$.

Wood decay test

A mini-block test comparable with the European standard (1996) EN 113 was carried out to assess fungal decay caused by basidiomycetes (Bravery 1978). DMDHEU- 
treated and untreated specimens were stored in a climate chamber at $20^{\circ} \mathrm{C}$ and $65 \%$ relative humidity for 2 weeks in order to reach moisture equilibration. The blocks were sterilised by gamma radiation $(25 \mathrm{kGy}$, Isotron, Netherlands). Petri dishes (145 mm diameter) with malt extract agar $(1.5 \%$ agar and $4 \%$ malt extract, $50 \mathrm{ml}$ per plate) were inoculated with a mycelium agar disc (5 mm diameter) taken from the sub-margin of 1-month-old cultures of $C$. puteana or $T$. versicolor. When the fungal mycelium reached the border of the plate (approx. 14 days), three untreated and three modified mini-blocks were aseptically added on separate metal grids (to avoid moisture uptake by the wood block). The plates were incubated at $22 \pm 1^{\circ} \mathrm{C}$ at $65 \%$ relative humidity for 12 weeks. Twelve wood samples for each treatment from four different plates were used to determine the mass loss of the wood blocks.

\section{Total esterase activity}

Wood mini-blocks which were incubated with wood decay fungi over different time periods (3, 6, 9 and 12 weeks) were taken from the plates, and the surface mycelium was removed. The blocks were crushed with a mortar and a pestle to small pieces (under ice cooling) and dispersed in $100 \mathrm{ml}$ of sterile $60 \mathrm{mmol}^{-1}$ sodium phosphate buffer solution ( $\mathrm{pH} 7.6)$ in an Erlenmeyer flask (500 ml). A stock solution of fluorescein diacetate (FDA, 3,6-diacetoxyfluran, $\mathrm{C}_{24} \mathrm{H}_{16} \mathrm{O}_{7}$; Sigma Chemical Co., St. Louis, USA) in acetone $\left(2 \mathrm{mg} \mathrm{ml}^{-1}\right)$ was added to reach a final FDA concentration of $10 \mu \mathrm{g} \mathrm{ml}^{-1}$. The flasks were incubated at room temperature on a rotary shaker $(120 \mathrm{rpm})$ for $1 \mathrm{~h}$ in total. After intervals of $15 \mathrm{~min}, 1 \mathrm{ml}$ aliquots were taken from the flasks and placed in Eppendorf tubes. The hydrolysis of FDA was terminated by addition of acetone to reach a final acetone concentration of $50 \%(v / v$; Schnürer and Rosswall 1982). The mixture was centrifuged for $5 \mathrm{~min}$ in a micro-centrifuge (IEC Micromax, Netherlands) at $10,000 \mathrm{rpm}$ to remove suspended particles. The amount of fluorescein released was measured (Specord 205, Analytic Jena, Germany) at the absorbance maximum of $494 \mathrm{~nm}$; esterase activity was expressed as milligram fluorescein which was released from FDA within 60 min (Kerem et al. 1992; Swisher and Carroll 1980; Schnürer and Rosswall 1982). Three individual wood blocks were used for each treatment to determine the activity.

\section{Micro-calorimetry}

Heat production was measured with a four channel microcalorimeter (Thermal Activity Monitor 2277, Thermometric, Jarvalla, Sweden) of heat conduction type and recorded using the program DIGITAM 2.0. Wood mini-blocks were incubated with wood decay fungi according to Bravery
(1978) as described above. After different incubation times (3, 6, 9 and 12 weeks), the wood samples were removed from the Petri dish and placed into a measuring ampoule $(25 \mathrm{ml})$ in order to determine the heat production. Three types of handling prior to the measurement were tested to assess if the method of sample removal from the agar plate has an effect on heat production. For the first method, the surface mycelium of each wood block was aseptically removed with a scalpel. For the second method, the same specimens were kept in sterile Petri dishes for 7 days at room temperature to allow the fungal mycelium to recover from primary injury. For the third method, the incubated samples were taken from the Petri dishes by cutting an agar block around the sample to minimise damage to the fungal hyphae. The sample was inserted into the measuring ampoule together with the agar block.

For the studies presented in Figs. 5 and 6, the first method was applied. During one measurement, heat production of three samples was simultaneously recorded; an empty ampoule served as a reference ampoule; un-inoculated wood did not produce detectable heat in the test. The three samples comprised one replicate for a specific treatment. Three replicates per treatment were tested in total.

All measurements were performed at $25^{\circ} \mathrm{C}$; during the measurement, the micro-calorimeter was located in a climatic chamber at constant temperature. Internal calibration was carried out at $3,000 \mu \mathrm{W}$ in the static mode. The detection limit was $\pm 9 \mu \mathrm{W}$ and baseline stability over $24 \mathrm{~h}$ was $\pm 15 \mu \mathrm{W}$. The ampoules were allowed to equilibrate for $1 \mathrm{~h}$ in the stand-by position before heat production data were recorded in intervals of $300 \mathrm{~s}$ over $20 \mathrm{~h}$. After the measurement, the samples were dried at $103^{\circ} \mathrm{C}$ and weighed. The amount of oxygen in the ampoules at the beginning of the measurement was calculated to be approx. $0.21 \mathrm{mmol}$. Oxygen consumption during the measurements was calculated based on the energy production according to Wieser (1986). Cumulative energy production $\left(E_{\text {total }}\right)[\mathrm{J}]$ was calculated from the following equation:

$E_{\mathrm{total}}=\sum_{i} \frac{Q_{i} \times t}{10^{6}}$

Where $Q_{i}=$ heat $[\mu \mathrm{W}]$ produced per time interval; $t=$ time interval (300 s).

\section{Results}

Mass loss of beech and pine wood caused by white and brown rot fungi

Beech and Scots pine wood blocks linearly increased in weight percentage gain after treatment with increasing 
concentrations of DMDHEU. Pine specimens displayed higher weight gains at a given concentration compared to beech due to their lower density (Table 1). During the decay test, all wood blocks were overgrown by surface mycelium independent of the WPG of the wood. Increasing WPG from DMDHEU treatment significantly decreased the mass loss in both beech and pine caused by the white rot fungus T. versicolor and the brown rot fungus C. puteana after fungal incubation (Fig. 1).

In beech, mass losses of the controls were greater than $60 \%$ after 12 weeks of incubation reflecting high activity of the tested fungi. At moderate and high WPG (approx. 13\% and $28 \%$ ), the mass loss in beech specimens was less than $6 \%$ with $T$. versicolor and less than $10 \%$ with $C$. puteana, while at low WPG (approx. $0.8 \%$ to $6.8 \%$ ), higher mass loss was observed for T. versicolor (approx. $45 \%$ ) and $C$. puteana $(18-26 \%)$.

Mass losses of pine sapwood controls were lower than those of beech wood controls, particularly with $T$. versicolor. As observed for modified beech wood, pine specimens with moderate and high WPG were minimally degraded by the fungi. In contrast to the degradation of beech wood, pine with low WPG $(1.3 \%)$ provided significant resistance against $T$. versicolor ( $6 \%$ mass loss), while $C$. puteana caused mass loss of $26 \%$.

\section{Total esterase activity}

TEA of T. versicolor in untreated beech wood was higher than that of $C$. puteana in untreated beech (Fig. 2a,b). T. versicolor promoted the highest fluorescein release of $60 \mu \mathrm{g} \mathrm{ml}^{-1}$ in untreated beech (after 6 weeks), while the maximum fluorescein release produced by C. puteana was only half of that of $T$. versicolor. Specimens with WPG between $3 \%$ and $10 \%$ incubated with $T$. versicolor displayed lower TEA than the controls. At high WPG, the activity of $T$. versicolor was barely above the detection limit. TEA of $C$. puteana in treated beech was less affected by WPG with mass loss due to decay being less than that for $T$. versicolor.

Similar results were obtained for the pine specimens (Fig. 2c,d). C. puteana showed the tendency that higher

Table 1 Weight percent gain (WPG) of beech and pine mini-blocks after treatment with DMDHEU solution of different concentrations

\begin{tabular}{lrr}
\hline $\begin{array}{l}\text { DMDHEU } \\
\text { concentration }[\mathrm{M}]\end{array}$ & WPG (beech) & WPG (pine) \\
\hline 0.12 & $1.0 \pm 0.2$ & $1.6 \pm 0.4$ \\
0.24 & $2.6 \pm 0.2$ & $3.5 \pm 0.6$ \\
0.40 & $6.6 \pm 0.6$ & $9.3 \pm 0.9$ \\
0.83 & $13.9 \pm 0.9$ & $18.4 \pm 3.7$ \\
1.77 & $27.6 \pm 1.4$ & $40.5 \pm 2.9$ \\
\hline
\end{tabular}
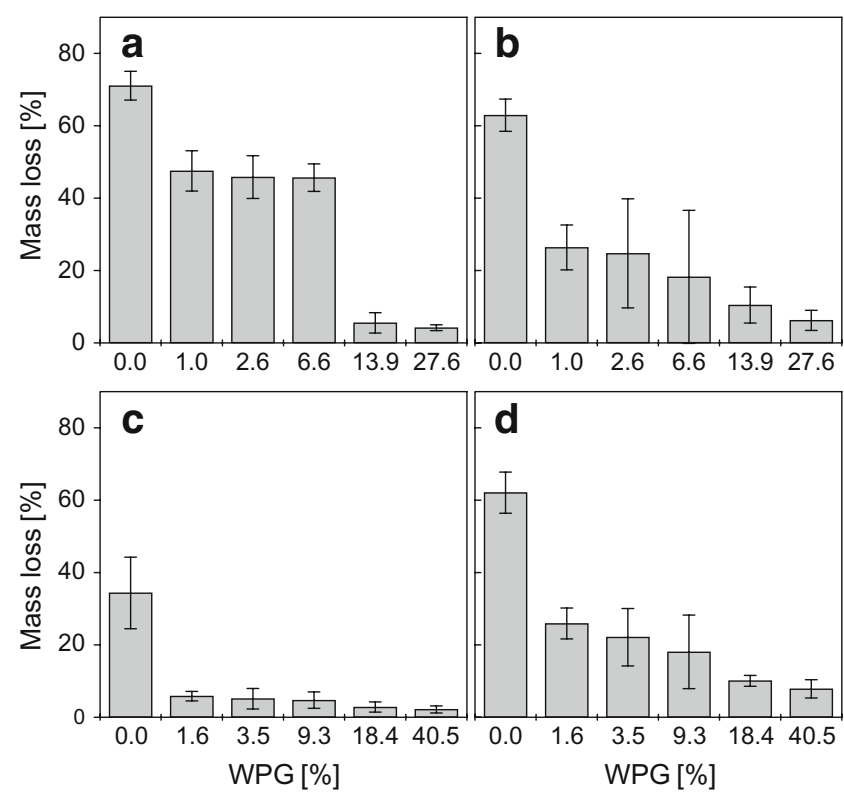

Fig. 1 Mass loss of untreated (control) and DMDHEU treated (0.12$1.77 \mathrm{mmol}^{-1}$ DMDHEU solution) mini-blocks after 12 weeks of fungal incubation. a T. versicolor, beech; b C. puteana, beech; c $T$. versicolor, pine; d C. puteana, pine (error bars show standard deviation, 12 replicates were used per treatment). WPG Weight percent gain of DMDHEU in the treated wood

WPG was concomitant with lower TEA; however, the differences between the treated specimens and the control were small, as with $C$. puteana in beech. T. versicolor in pine, however, showed considerable differences between the treated specimens and the control. The activity of all

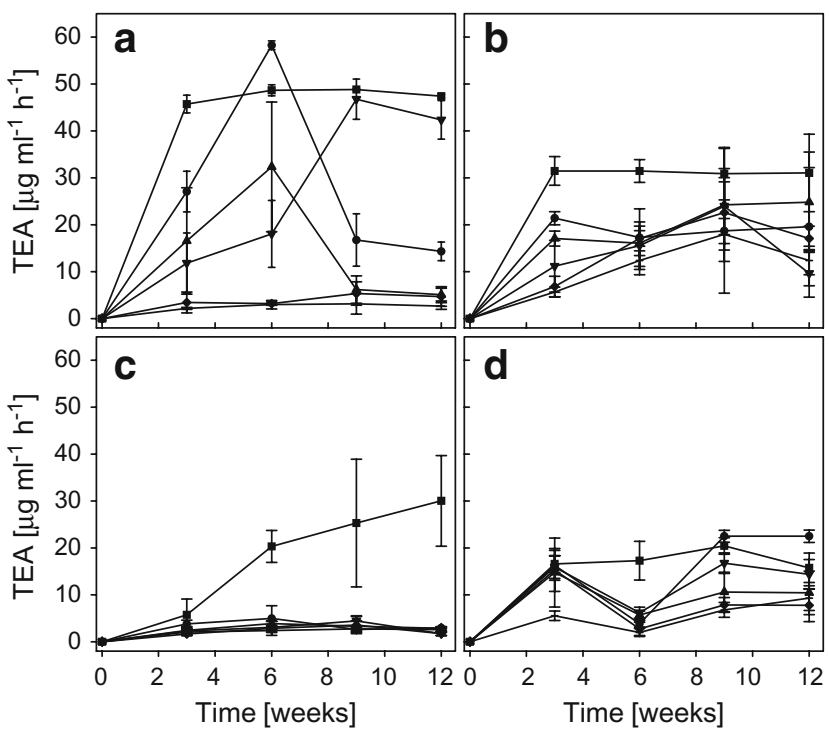

$\rightarrow$ Control $\rightarrow 0.12 \mathrm{M} \longrightarrow 0.24 \mathrm{M} \rightarrow 0.40 \mathrm{M} \rightarrow 0.83 \mathrm{M} \longrightarrow 1.77 \mathrm{M}$

Fig. 2 Total esterase activity in untreated (control) and DMDHEU treated wood (0.12-1.77 mmol $1^{-1}$ DMDHEU solution) determined as release of fluorescein from fluorescein diacetate (FDA). a T. versicolor, beech; b C. puteana, beech; c T. versicolor, pine; d C. puteana, pine (error bars show standard deviation; three replicates were used per treatment) 


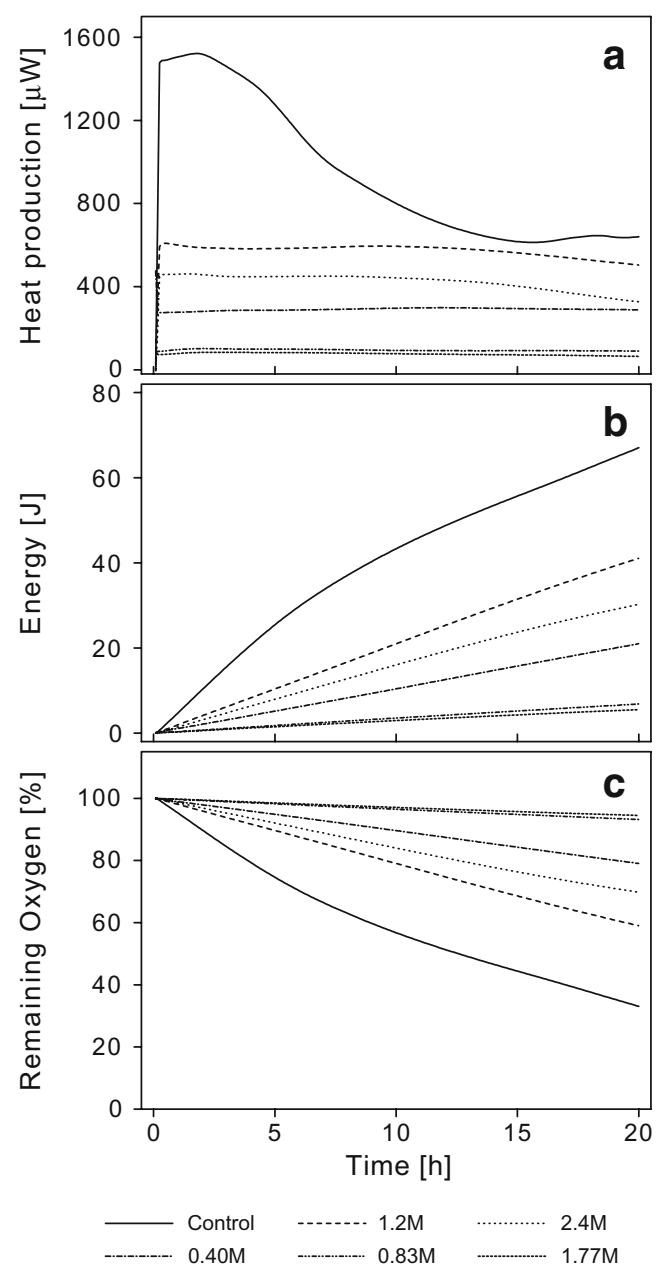

Fig. 3 Heat production measured in a micro-calorimeter (a), energy production (b) and oxygen consumption (c) of $T$. versicolor in untreated (control) and DMDHEU treated $\left(0.12-1.77 \mathrm{mmol}^{-1}\right.$ DMDHEU solution) beech wood mini-blocks after 3 weeks of incubation

treated samples was close to the detection limit. Thus, TEA activity differences between them were not detectable. In the pine controls incubated with $T$. versicolor, TEA (Fig. 2c) continuously increased for 12 weeks. With all other fungi and wood species, maximum values of TEA were reached between 6 and 9 weeks.

\section{Heat and energy production}

The thermograms of $T$. versicolor in untreated and modified beech wood (Fig. 3a) displayed typical courses of heat production after 3 weeks of incubation on agar plates. Heat production started immediately showing a maximum after approx. $2 \mathrm{~h}$. In the untreated controls, the rate of heat production decreases quickly after that peak, while it remained almost constant in the treated samples. As a consequence, total energy production, which was calculated from the cumulative heat production, did not proceed linearly over longer measurement periods when heat production was high (Fig. 3b). On average, only $40 \%$ of the initial oxygen in the ampoules with untreated beech wood remained after $17 \mathrm{~h}$ (Fig. 3c).

The removal of mycelium from the wood surface injured the hyphae potentially inducing primary metabolic activity of the fungi. In most cases, energy production was higher when the wood blocks were removed together with the agar which potentially damaged less of the mycelia (Fig. 4). However, the agar would also have included more of the fungal biomass and this could also explain the larger energy values. In pine, the energy production of specimens incubated for 7 days after removal of surface mycelium was reduced by up to $46 \%$ compared to measurements taken directly after removal of mycelium (after 12 weeks of fungal incubation); these differences, however, were less for the samples measured after 6 weeks of incubation. The greatest differences were observed with $C$. puteana in beech. In this case, however, energy production after removal of mycelium displayed high standard deviation.

As with total esterase activity, T. versicolor produced more heat energy in beech (Fig. 5a) than in pine wood

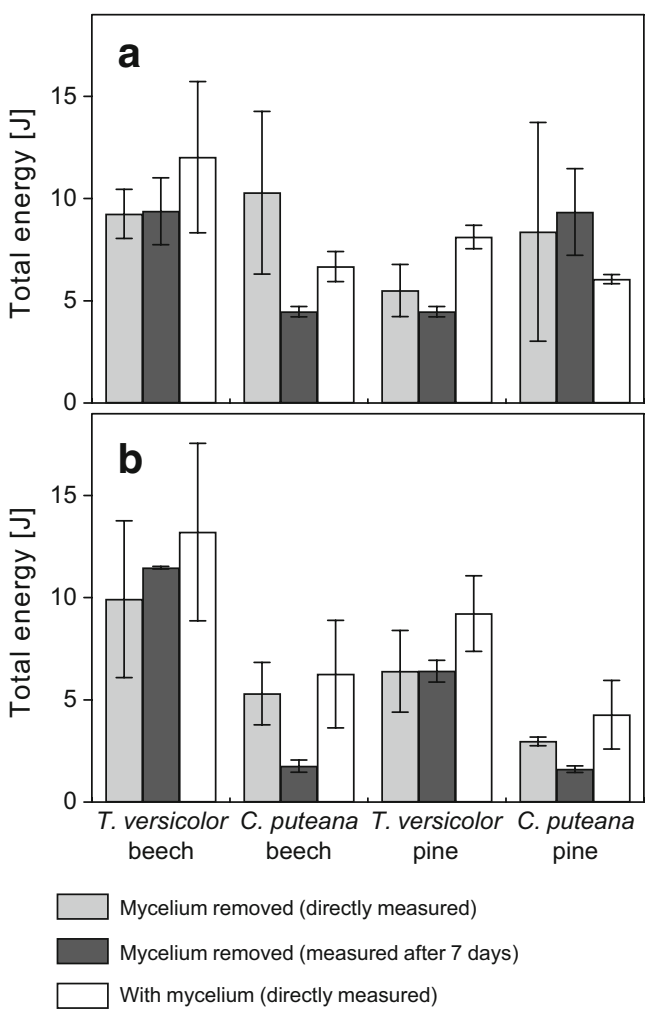

Fig. 4 Total energy production of decay fungi in wood mini-blocks during $3 \mathrm{~h}$ measuring time. Heat production was recorded directly after removal of surface mycelium from the wood block, 7 days after the removal of surface mycelium, without removal of surface mycelium (wood block still placed on an agar block that after incubation was cut from the medium around the sample to minimise damage to the fungal hyphae). a 6 weeks of incubation, b 12 weeks of incubation (error bars show standard deviation; three replicates were used per treatment) 
Fig. 5 Total energy production of decay fungi in untreated (control) and DMDHEU treated (0.12-1.77 $\mathrm{mmol} \mathrm{l}^{-1}$ DMDHEU solution) beech mini-blocks during $3 \mathrm{~h}$ measuring time. After the indicated incubation times on malt agar plates, the surface mycelium of each wood block was aseptically removed and the activity in the blocks directly determined. a Energy production and $\mathbf{b}$ mass loss caused by $T$. versicolor; c energy production and $\mathbf{d}$ mass loss caused by C. puteana (error bars show standard deviation; three replicates were used per treatment)

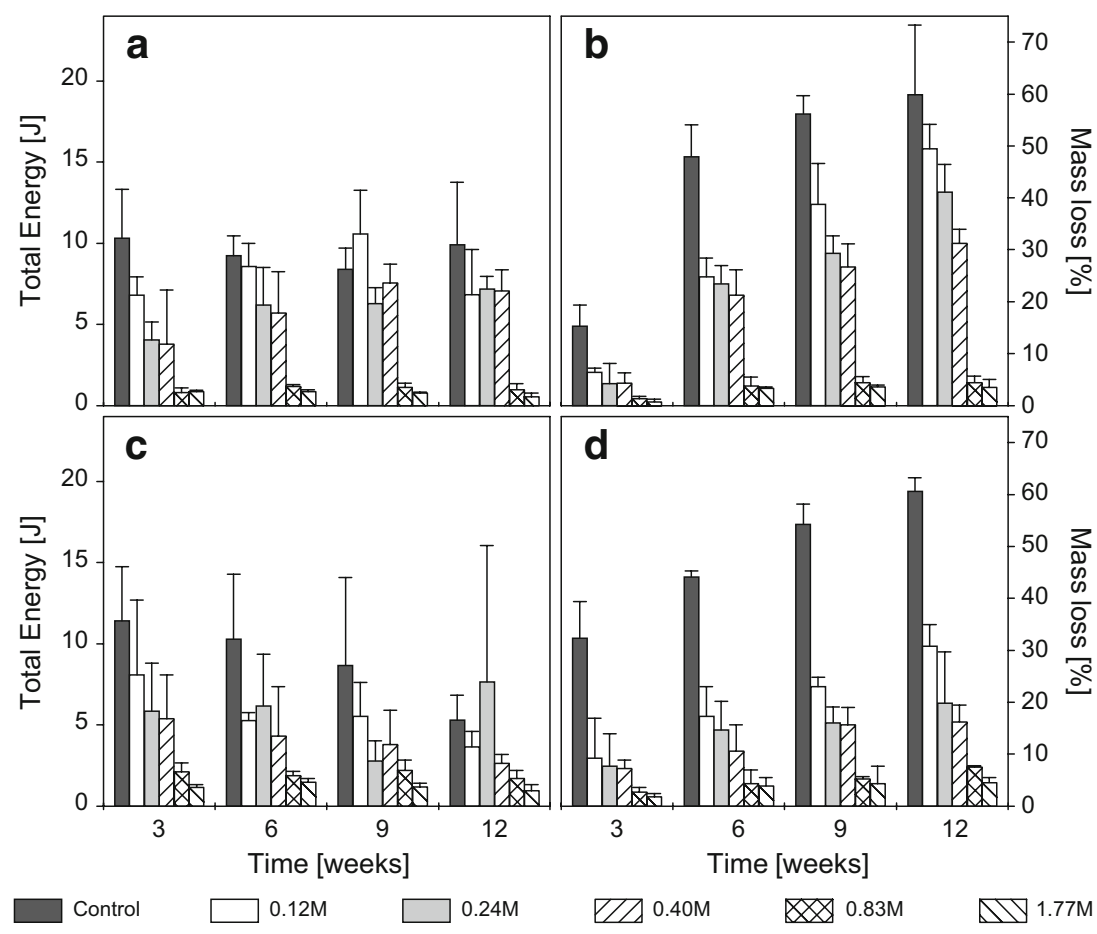

(Fig. 6a). Energy production, however, did not always follow the same course as TEA. T. versicolor in untreated beech and in beech treated with low DMDHEU concentration (Fig. 5a) produced similar amounts of energy as $C$. puteana in the corresponding specimens (Fig. 5c). In contrast, TEA of T. versicolor in untreated beech (Fig. 2a) was much higher than that of $C$. puteana in corresponding specimens (Fig. 2b).

A comparison of both fungal species in the untreated beech samples revealed that $T$. versicolor and $C$. puteana (Fig. 5b,d) degraded the wood at comparable rates. In the pine specimens, $C$. puteana reached a maximum mass loss
Fig. 6 Total energy production of decay fungi in untreated (control) and DMDHEU treated (0.12-1.77 $\mathrm{mmol} \mathrm{l}^{-1}$ DMDHEU solution) pine mini-blocks during $3 \mathrm{~h}$ measuring time. After the indicated incubation times on malt agar plates, the surface mycelium of each wood block was aseptically removed and the activity in the blocks directly determined. a Energy production and $\mathbf{b}$ mass loss caused by T. versicolor; c energy production and $\mathbf{d}$ mass loss caused by C. puteana (error bars show standard deviation; three replicates were used per treatment)

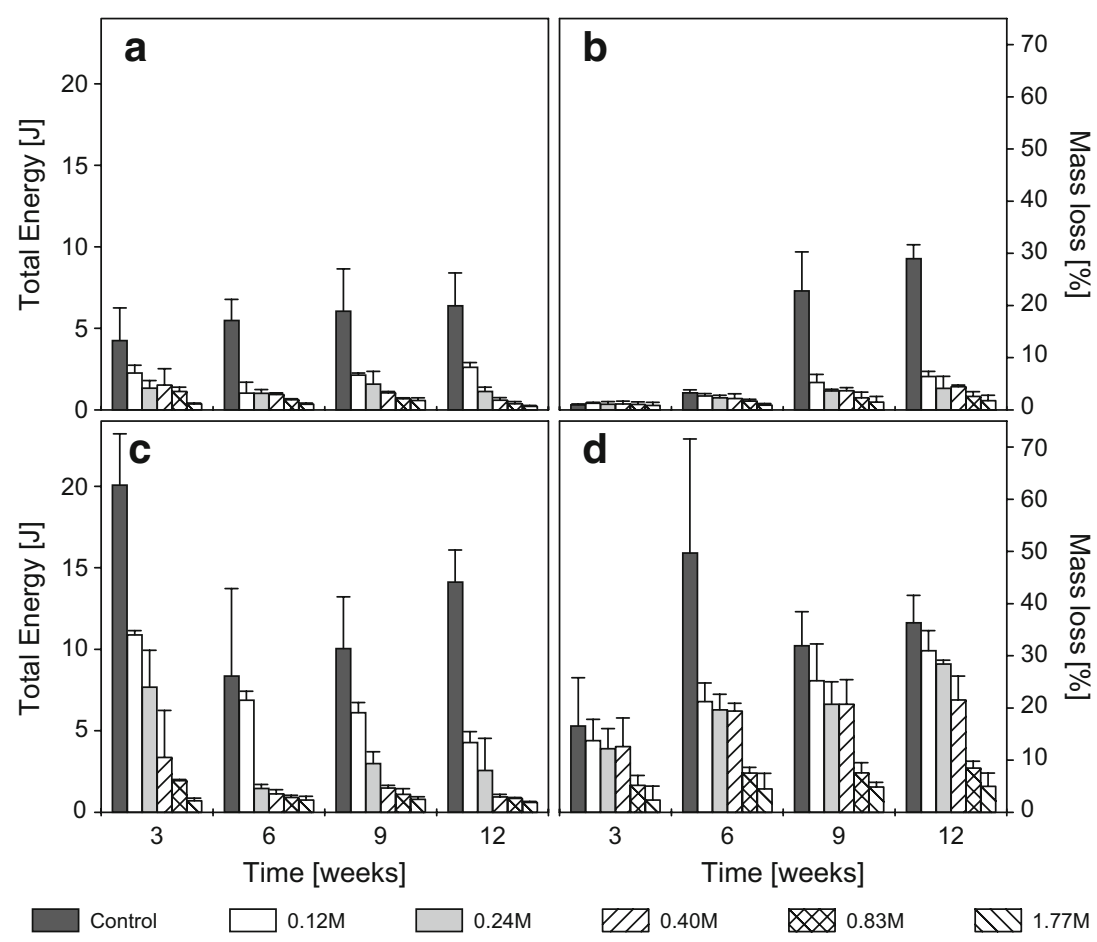


$(50 \%)$ after 6 weeks (however, the standard deviation was high), yet energy production continually increased from 6 to 12 weeks of incubation (Fig. 6c,d).

Overall, the energy production of both fungi in beech and pine tended to decrease with increasing weight gain of DMDHEU and, thus, reflected the differences in mass loss during fungal incubation (Figs. 5 and 6). Specimens treated with $0.12,0.24$ and $0.40 \mathrm{~mol}^{-1}$ of DMDHEU displayed considerable energy production with both fungi and wood species, while higher treatment concentrations $(0.83$ and $1.77 \mathrm{~mol} \mathrm{l}^{-1}$ ) reduced energy production significantly. $C$. puteana showed higher energy production in high WPG $\left(0.83\right.$ and $\left.1.77 \mathrm{~mol}^{-1}\right)$ beech and pine samples compared to $T$. versicolor. This reflected the higher mass loss caused by $C$. puteana (compare Fig. $5 \mathrm{~b}$ and d, as well as Fig. 1a and $b$ ) in high WPG samples and this is also in agreement with the TEA data.

\section{Discussion}

Decay of beech and pine sapwood by $T$. versicolor and $C$. puteana was strongly affected by DMDHEU treatment. Except for T. versicolor in beech, even treatment with the lowest concentration of DMDHEU $\left(0.12 \mathrm{~mol} \mathrm{l}^{-1}\right)$ reduced the mass loss of all specimens by more than $50 \%$ compared to the controls. In beech, treatment with low DMDHEU concentrations provided increased protection against $C$. puteana (lower mass loss) than against $T$. versicolor, while in pine, DMDHEU was more effective against $T$. versicolor. This effect might be explained by the preference of brown rot fungi for softwoods and of white rot fungi for hardwoods (Eaton and Hale 1993). Beech wood is a more natural habitat for $T$. versicolor than pine. Therefore, the fungus can obviously cope with higher levels of DMDHEU treatment in beech than in pine wood. C. puteana, on the other hand, did not show significant differences in mass loss in comparing beech and pine.

DMDHEU monomers were recently shown not to have a negative effect on the growth of the two fungi tested, when the chemical was added to agar growth medium (Verma et al. 2005). The lack of toxicity of DMDHEU has also been shown by its rather high LD50 (>10,000 mg kg-1) for rats (OECD SIDS 2000). Thus, a biocidal effect of unreacted monomers cannot explain the reduction in mass loss. However, the modification of beech and pine wood with DMDHEU to a WPG greater than $10 \%$ provided a level of protection against $T$. versicolor and $C$. puteana, comparable to that of conventional wood preservatives.

Increasing the WPG of DMDHEU also resulted in lower metabolic activity of the infecting fungi. Energy production and TEA were observed at the highest WPG, and this metabolic activity emanated from fungal hyphae within the wood blocks as the surface mycelium was removed prior to measurement. These results show that the fungi were not only able to overgrow, but also to colonise the wood blocks. The ability to colonise the wood, was also confirmed through microscopy which showed the presence of hyphae in the cells of modified wood (not shown). At high WPG, the fungi are able to grow into the wood and use readily available nutrients such as simple sugars, minerals, proteins or vitamins in the parenchyma cells. The degree of colonisation, however, remains low, since the fungi are not able to make nutrients accessible by degradation of cell wall polymers. In addition, the fungi do not seem to be able to transport sufficient amounts of nutrients from the outer agar medium into the wood.

Three main mechanisms have previously been cited to explain high resistance of chemically modified wood against fungal decay (Hill 2006): reduction of the moisture content (fibre saturation point), changes of the cell wall polymers to make these polymers unrecognisable for enzymes and/or a lower micro-pore size in the wood cell wall. It is assumed that cell wall bulking and micro-pore blocking can effectively inhibit the penetration of low molecular weight diffusible agents, which is required for fungal degradation (Papadopoulos and Hill 2002; Hill et al. 2005).

The esterase activity and heat production did not always follow the same trends. In both fungi, the energy production appeared to be rather constant over the total incubation time (12 weeks), while FDA hydrolysis remained variable. This could be the result of a higher systematic error, e.g. related to enzyme extraction during TEA determination. The colonisation of the wood specimens was not confirmed by mass loss determination because the procedure required crushing and destruction of the samples.

Injury during the removal of mycelium from the wood surface did not seem to induce the metabolic activity (e.g. heat production) in the fungi. Heat production was higher, when the injury was minimised by removing agar together with the wood block (still, considerable injury of hyphae occurred in the agar block). This might be explained by greater fungal biomass in the agar. Specimens kept under sterile conditions to allow the mycelium to recover from injury showed a reduced activity. This could also be explained as the effect of non-optimal storage conditions (drying and surface death of mycelial cells), rather than a reduction in activity after remediation of the injury.

During calorimetry, fungal activity was strongly affected by respiration, particularly at higher energy production levels. It was previously reported that high carbon dioxide concentrations affect fungal activity stronger than a lack of oxygen (Scheffer 1986; Ljungholm et al. 1979; Sparling 1983). 


\section{Conclusion}

Determination of total esterase activity and metabolic heat (energy) in a micro-calorimeter are suitable methods for determining the fungal activity in decaying wood. Both methods provide measures of fungal primary metabolism; however, secondary metabolism also contributes to heat production. Micro-calorimetry, in particular, is a nondestructive method for rapid screening of wood preservatives or novel wood modification technologies. Moreover, it provides a method to relate mass loss and fungal activity in wood.

Wood modified with DMDHEU showed reductions in mass loss during fungal incubation, but even at the highest WPG the fungi were able to colonise the treated wood. The extent of both mass loss and fungal activity in the wood was related to the WPG by the extent of cell wall alteration. The DMDHEU in the wood has been shown not be toxic to the fungi and rather, the mode of action of DMDHEU in imparting high durability to the wood is different from conventional biocides.

Acknowledgements The authors are grateful to the German Science Foundation (DFG) for supporting this project. They would also like to thank Prof. Jody Jellison and Prof. Barry Goodell for fruitful discussions and for their sound advice.

Open Access This article is distributed under the terms of the Creative Commons Attribution Noncommercial License which permits any noncommercial use, distribution, and reproduction in any medium, provided the original author(s) and source are credited.

\section{References}

Akitsu H, Norimoto N, Morooka T, Rowell RM (1993) Effect of humidity on vibrational properties of chemically modified wood. Wood Fiber Sci 25:250-260

Belaich JP (1980) Growth and metabolism in bacteria. In: Beezer AE (ed) Biological microcalorimetry. Academic, London, pp 1-42

Bjurman J (1992) ATP assay for the determination of mould activity on wood at different moisture conditions. International Research Group on Wood Protection (IRG/WP 92-2397), Stockholm

Bjurman J (1993) Determination of microbial activity in moulded wood by the use of fluorescein diacetate. Mater Org 28:1-16

Bjurman J (1994) Ergosterol as an indicator of mould growth on wood in relation to culture age, humidity stress and nutrient level. Int Biodeterior Biodegrad 33:355-386

Bjurman J, Wadsö L (2000) Microcalorimetric measurements of metabolic activity of six decay fungi on spruce wood as a function of temperature. Mycologia 92:23-28

Bravery AF (1978) A miniaturized wood block for the rapid evaluation of wood preservative fungicides. International Research Group on Wood Protection (IRG/WP 2113), Stockholm

Criddle RS, Fontana AJ, Rank DR, Paige D, Hansen LD, Breidenbach RW (1991) Simultaneous measurement of metabolic heat rate, $\mathrm{CO}_{2}$ production, and $\mathrm{O}_{2}$ consumption by microcalorimetry. Anal Biochem 194:413-417
Dermoun Z, Belaich JP (1980) Micro-calorimetric studies of Escherichiacoli aerobic growth - theoretical aspects of growth on succinic acid. J Bacteriol 143:742-746

Donath S, Miliz H, Mai C (2004) Wood modification with alkoxysilanes. Wood Sci Technol 38:555-566

Dyckmans J, Flessa H, Lipski A, Potthoff M, Beese F (2006) Microbial biomass and activity under oxic and anoxic conditions as affected by nitrate additions. J. Plant Nutr Soil Sci 169: $108-115$

Eaton RA, Hale MDC (1993) Wood: decay, pests and protection, 1st edn. Chapman and Hall, London

European Standard (1996) EN 113. Wood preservatives - method of test for determining the protective effectiveness against wood destroying basidiomycetes - determination of the toxic values, CEN, technical committee TC 38

Ginterova A, Lazariva A (1989) Energy transformation of lignocellulosics into fruit bodies of the wood-rotting fungus Pleurotus ostreatus. Folia Microbiol 34:141-145

Goldstein IS, Jeroski EB, Lund AE, Nielson JF, Weaver JW (1961) Acetylation of wood in lumber thickness. For Prod J 11:363-370

Guilbault GG, Kramer DN (1964) Fluorometric determination of lipase, acylase, alpha- and gamma-chymotrypsin and inhibitors of these enzymes. Anal Chem 36:409-412

Hill CAS (2006) Wood modification. Chemical, thermal and other processes. Wiley, Chichester

Hill CAS, Jones D (1996) The dimensional stabilisation of Corsican pine sapwood by reaction with carboxylic acid anhydride. The effect of chain length. Holzforschung 50:457-462

Hill CAS, Jones D (1999) Dimensional changes in Corsican pine sapwood due to chemical modification with linear chain anhydrides. Holzforschung 53:267-271

Hill CAS, Forster SC, Farahani MRM, Hale MDC, Ormondroyd GA, Williams GR (2005) An investigation of cell wall micropore blocking as a possible mechanism for the decay resistance of anhydride modified wood. Int Biodeterior Biodegrad 55:69-76

Kabir FRA, Nicholas DD, Vasishth RC, Barnes HM (1992) Laboratory methods to predict the weathering characteristics of wood. Holzforschung 46:395-401

Kerem ZD, Friesem Y, Hadar Y (1992) Lignocellulose degradation during solid state fermentation: Pleurotus osteratus versus Phanerochaete chrysosporium. Appl Environ Microbiol 58:1121-1127

Kwon JH, Hill CAS, Ormondroyd GA, Karim S (2007) Changes in the cell wall volume of a number of wood species due to reaction with acetic anhydride. Holzforschung 61:138-142

Lande S, Eikenes M, Westin M (2004) Chemistry and ecotoxicology of furfurylated wood. Scand J For Res 19(Suppl. 5):14-21

Larsson C, Liden G, Niklasson C, Gustafsson L (1991) Calorimetric control of fed-batch cultures of Saccharomyces cerevisiae. Bioprocess Eng 7:151-155

Ljungholm K, Noren B, Skold R, Wadsö I (1979) Use of microcalorimetry for the characterization of microbial activity in soil. Oikos 33:15-23

Militz H (1991) Die Verbesserung des Schwind- und Quellverhaltens und der Dauerhaftigkeit von Holz mittels Behandlung mit unkatalysiertem Essigsäureanhydrid. Holz Roh Werkst 49:147-152

Militz H (1993) Treatment of timber with water-soluble dimethylol resin to improve their dimensional stability and durability. Wood Sci Technol 27:347-357

Mohebby B, Militz H (2002) Soft rot decay in acetylated wood. Chemical and anatomical changes in decayed wood. International Research Group on Wood Protection (IRG/WP 02-40231), Stockholm

Norimoto M (2001) Chemical modification of wood. In: Hon DNS, Shiraishi N (eds) Wood and cellulosic chemistry. 2nd edn. Dekker, New York, pp 573-598 
OECD SIDS (2000) SIDS Initial Assessment Report for 10th SIAM, UNEP Publications, (Tokyo, 15-17 March 2000), http://www. inchem.org/documents/sids/sids/1854268.pdf

Ohkoshi M, Kato Suzuki A, Hayashi K, Ishihara N (1999) Characterization of acetylated wood decayed by brown rot and white rot fungi. J Wood Sci 45:69-75

Ölz R, Larsson K, Adler L, Gustafsson L (1993) Energy flux and osmoregulation of Saccharomyces cerevisiae grown in chemostats under $\mathrm{NaCl}$ stress. J Bacteriol 175:2205-2213

Papadopoulos AN, Hill CAS (2002) The biological effectiveness of wood modified with linear chain carboxylic acid anhydrides against Coniophora puteana. Holz Roh Werkst 60:329-332

Ritschkoff AC, Rättö M, Nurmi A, Kokko H, Rapp A, Militz H (1999) Effect of resin treatment on fungal degradation reactions. International Research Group on Wood Protection (IRG/WP 9910318), Stockholm

Rowell RM (1983) Chemical modification of wood. For Prod Abstr 6:366-382

Rowell RM (2006) Acetylation of wood-journey from analytical technique to commercial reality. For Prod J 56(9):4-12

Saxena G, Lysek G (1993) Observation of nematophagous fungi in natural soils by fluorescence microscopy and their correlation with isolation. Mycol Res 97:1005-1011, Part 8

Scheffer TC (1986) $\mathrm{O}_{2}$ requirements for growth and survival of wood-decaying and sapwood-staining fungi. Can J Bot 64:19571963

Schnürer J, Rosswall T (1982) Fluorescein diacetate hydrolysis as a measure of total microbial activity in soil and litter. Appl Environ Microbiol 43:1256-1261
Sparling GP (1983) Estimation of microbial biomass and activity in soil using microcalorimetry. J Soil Sci 34:381-390

Swisher R, Carroll GC (1980) Fluorescein diacetate as an estimator of microbial biomass on coniferous needle surface. Microb Ecol 6:217-226

Verma P, Mai C, Krause A, Militz H (2005) Studies on the resistance of DMDHEU treated wood against white-rot and brown-rot fungi. International Research Group on Wood Protection (IRG/ WP 05-10566), Stockholm

Vor T, Dyckmans J, Flessa H, Beese F (2002) Use of microcalorimetry to study microbial activity during the transition from oxic to anoxic conditions. Biol Fert Soils 36(1):66-71

Weigenand O, Humar M, Daniel G, Militz H, Mai C (2008) Decay resistance of wood treated with amino-silicone compounds. Holzforschung 62:112-118

Wieser W (1986) Bioenergetik. Thieme, Stuttgart, pp 35-46

Xie Y, Bjurman J, Wadsö L (1997) Microcalorimetric characterization of the recovery of a brown rot fungus after exposures to high and low temperature, oxygen depletion and drying. Holzforschung 51:201-206

Yano H, Minato K (1993) Controlling the timber of wooden musical instruments by chemical modification. Wood Sci Technol 27:287-293

Yasuda R, Minato K (1994) Chemical modification of wood by nonformaldehyde cross-linking reagents-Part 1. Improvement of dimensional stability and acoustic properties. Wood Sci Technol 28:101-110

Yusuf S (1996) Properties enhancement of wood by cross-linking formation and its application to the reconstituted wood products. Wood Res 83:140-209 